\title{
Use of Chiral lonic Liquids as Solvents for the Enantioselective Photoisomerization of Dibenzobicyclo[2.2.2]octatrienes
}

\section{Supporting Information}

\author{
Jie Ding, Vasumathi Desikan, Xinxin Han, Tom L. Xiao, Rongfang Ding, William S. Jenks \\ and Daniel W. Armstrong* \\ Chemistry Department, Iowa State University, Ames, IA, 50011
}

$\begin{array}{lc}\text { Materials preparations } & \text { S2 } \\ \text { Description of photolyses } & \text { S3 } \\ \text { Spectra for compounds } & \text { S5 }\end{array}$ 


\section{Materials}

The preparation of $\mathbf{1 b}$ and $\mathbf{1 c}$ followed the method of Diels and Alder. ${ }^{1}$ The synthesis of the enantiomers of ionic liquid $\mathbf{3}$ is also described elsewhere. ${ }^{2}$

Ionic liquid 4. Each enantiomer was prepared separately from the corresponding commercially available (+) or (-) chloromethyl menthyl ether. The (+) ether $(5.0 \mathrm{~g}, 24.4$ mmol)) was added dropwise over $30 \mathrm{~min}$ to a solution of 1-methylimidazole (2.0 g, 24.4 $\mathrm{mmol}$ ) in $300 \mathrm{~mL} \mathrm{1,1,1-trichloroethane} \mathrm{in} \mathrm{a} \mathrm{flask} \mathrm{equipped} \mathrm{with} \mathrm{a} \mathrm{stirrer} \mathrm{and} \mathrm{reflux}$ condenser. The mixture was stirred for an additional $0.5 \mathrm{~h}$ and then evaporated to dryness. The resultant white powder was dissolved in $100 \mathrm{~mL}$ water. Addition of an aqueous solution of $N$-lithiotrifluoromethanesulfonimide $(7.0 \mathrm{~g}, 24.4 \mathrm{mmol})$ led to the separation of an ionic liquid phase, which then was washed three times with $15 \mathrm{~mL}$ portions of water. The final product was heated under reduced pressure at $100{ }^{\circ} \mathrm{C}$ to eliminate the remaining water: yield $11.7 \mathrm{~g}, 90 \%$; ${ }^{1} \mathrm{H}-\mathrm{NMR}(300 \mathrm{MHz}, \mathrm{DMSO}-d 6) \delta 9.32(\mathrm{~s}, 1 \mathrm{H}), 7.91(\mathrm{t}, J=1.8 \mathrm{~Hz}, 1 \mathrm{H}), 7.75(\mathrm{t}$, $J=1.8 \mathrm{~Hz}, 1 \mathrm{H}), 5.58\left(\mathrm{AB}, J_{A B}=10.8 \mathrm{~Hz}, \Delta v=8.1 \mathrm{~Hz}, 2 \mathrm{H}\right), 3.89(\mathrm{~s}, 3 \mathrm{H}), 3.24\left(\mathrm{dt}, J_{1}=10.5\right.$ $\left.\mathrm{Hz}, J_{2}=4.2 \mathrm{~Hz}, 1 \mathrm{H}\right), 2.10-2.01(\mathrm{~m}, 1 \mathrm{H}), 1.94-1.84(\mathrm{~m}, 1 \mathrm{H}), 1.63-1.54(\mathrm{~m}, 2 \mathrm{H}), 1.45-1.28(\mathrm{~m}$, $1 \mathrm{H}), 1.20-1.08(\mathrm{~m}, 1 \mathrm{H}), 0.95-0.74(\mathrm{~m}, 3 \mathrm{H}), 0.90(\mathrm{~d}, J=6.6 \mathrm{~Hz}, 3 \mathrm{H}), 0.80(\mathrm{~d}, J=7.2 \mathrm{~Hz}, 3 \mathrm{H})$, $0.40(\mathrm{~d}, J=6.9 \mathrm{~Hz}, 3 \mathrm{H})$. The specific rotation $([\alpha])$ was determined at $20^{\circ} \mathrm{C}$ using the $\mathrm{D}$ line of sodium. The measured values for (+)-IL 4 and (-)-IL 4 were $54.6^{\circ}$ and $-54.6^{\circ}$, respectively. MS peaks at m/z 251 and 280 were observed in positive and negative ion modes, respectively.

Ionic liquid 5: An aqueous solution of $N$-lithiotrifluoromethanesulfonimide $(7.7 \mathrm{~g}$, $26.8 \mathrm{mmol})$ was added to an aqueous solution of $\mathrm{D}(+)$-carnitinenitrile chloride $(4.8 \mathrm{~g}, 26.8$ mmol). The ionic liquid layer was washed three times with $15 \mathrm{~mL}$ portions of water. The 
remaining water was then removed under high vacuum at $100^{\circ} \mathrm{C}$ : yield $10.6 \mathrm{~g}, 85 \% ;{ }^{1} \mathrm{H}$ NMR (300 MHz, DMSO-d6) $\delta 6.15(\mathrm{~d}, J=5.1 \mathrm{~Hz}, 1 \mathrm{H}), 4.48-4.35(\mathrm{~m}, 1 \mathrm{H}), 3.40-3.37(\mathrm{~m}$, $2 \mathrm{H}), 3.13(\mathrm{~s}, 9 \mathrm{H}), 2.76\left(\mathrm{dd}, J_{l}=16.8 \mathrm{~Hz}, J_{2}=4.8 \mathrm{~Hz}, 1 \mathrm{H}\right), 2.69\left(\mathrm{dd}, J_{1}=16.8 \mathrm{~Hz}, J_{2}=6.0\right.$ $\mathrm{Hz}, 1 \mathrm{H})$. The specific rotation of IL-5 is $12.9^{\circ}$. MS peaks at $\mathrm{m} / \mathrm{z} 143$ and 280 were observed in positive and negative ion modes, respectively.

Ionic liquid 6: The first step to make IL 6 has been reported previously. ${ }^{3}$ After getting the chloride salt, an ion metathesis reaction using $N$-lithiotrifluoromethanesulfonimide as described previously was followed at a 1:1 ratio to produce the final ionic liquid. Overall yield $30 \% ;{ }^{1} \mathrm{H} \mathrm{NMR}\left(300 \mathrm{MHz}, \mathrm{CDCl}_{3}\right) \delta 8.99$ (s, 1H), $7.44-7.32(\mathrm{~m}, 10 \mathrm{H}), 7.15-7.14(\mathrm{~m}, 2 \mathrm{H}), 5.72(\mathrm{q}, J=6.9 \mathrm{~Hz}, 2 \mathrm{H}), 1.95(\mathrm{~d}, J=6.9 \mathrm{~Hz}$, $6 \mathrm{H})$. The specific rotation of IL-6 is $5.8^{\circ}$. MS peaks at $\mathrm{m} / \mathrm{z} 277$ and 280 were observed in positive and negative ion modes, respectively.

\section{Photolyses}

For each entry in the Table, diacid $1 \mathrm{c}(5.8 \mathrm{mg}, 20 \mathrm{mmol})$ was dissolved in $2 \mathrm{~mL}$ of the respective $\mathrm{IL}$ in a $3 \mathrm{~mL}$ quartz cuvette. After purging with argon for $10 \mathrm{~min}$, the photolysis was carried out in a Rayonet reactor with four $300 \mathrm{~nm}$ broadly emitting UV lamps. Product formation was followed by NMR.

To quantify yields, HPLC with UV detection was used. Standard absorption curves were constructed from isolated products obtained from preparative HPLC isolations.

Enantiomers could be separated using a Cyclobond AC column $(250$ x $4.6 \mathrm{~mm}, 5 \mu \mathrm{m}$ particle size, Astec), and routine detection was done using UV absorption at $220 \mathrm{~nm}$. The mobile phase was 30:70 (v:v) methanol : $0.2 \%$ TEA $+0.1 \% \mathrm{H}_{3} \mathrm{PO}_{4}$ aqueous solution at a flow rate of $1.0 \mathrm{~mL} / \mathrm{min}$. The optical rotation of the product enantiomers was established at Astec by use 
of a Chiralyzer ${ }^{\mathrm{TM}}$ LC polarimetric detector with a similar mobile phase mixture and identical column. The first-eluting enantiomer has a positive optical rotation at 430nm.

Secondary photolysis of $\mathbf{2 c}$ was not significant until very high conversions (about $90 \%$ or greater). Secondary photolysis of $\mathbf{2} \mathbf{b}$ was more significant at lower conversions; new products were observed at conversions of approximately $50 \%$ and greater. No effort was made to identify the secondary photolysis products, and the analysis of enantiomeric excess was limited to $\mathbf{2 b}$ and $\mathbf{2 c}$. 
Spectra for 4 .

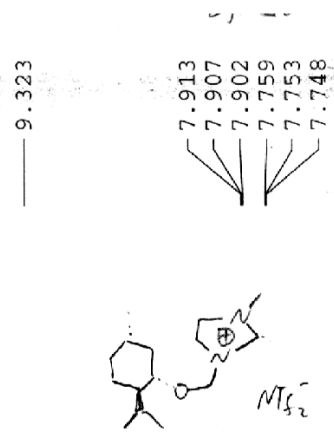

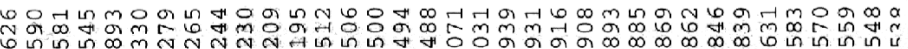

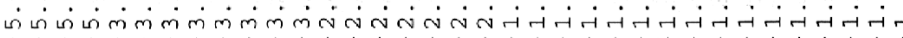
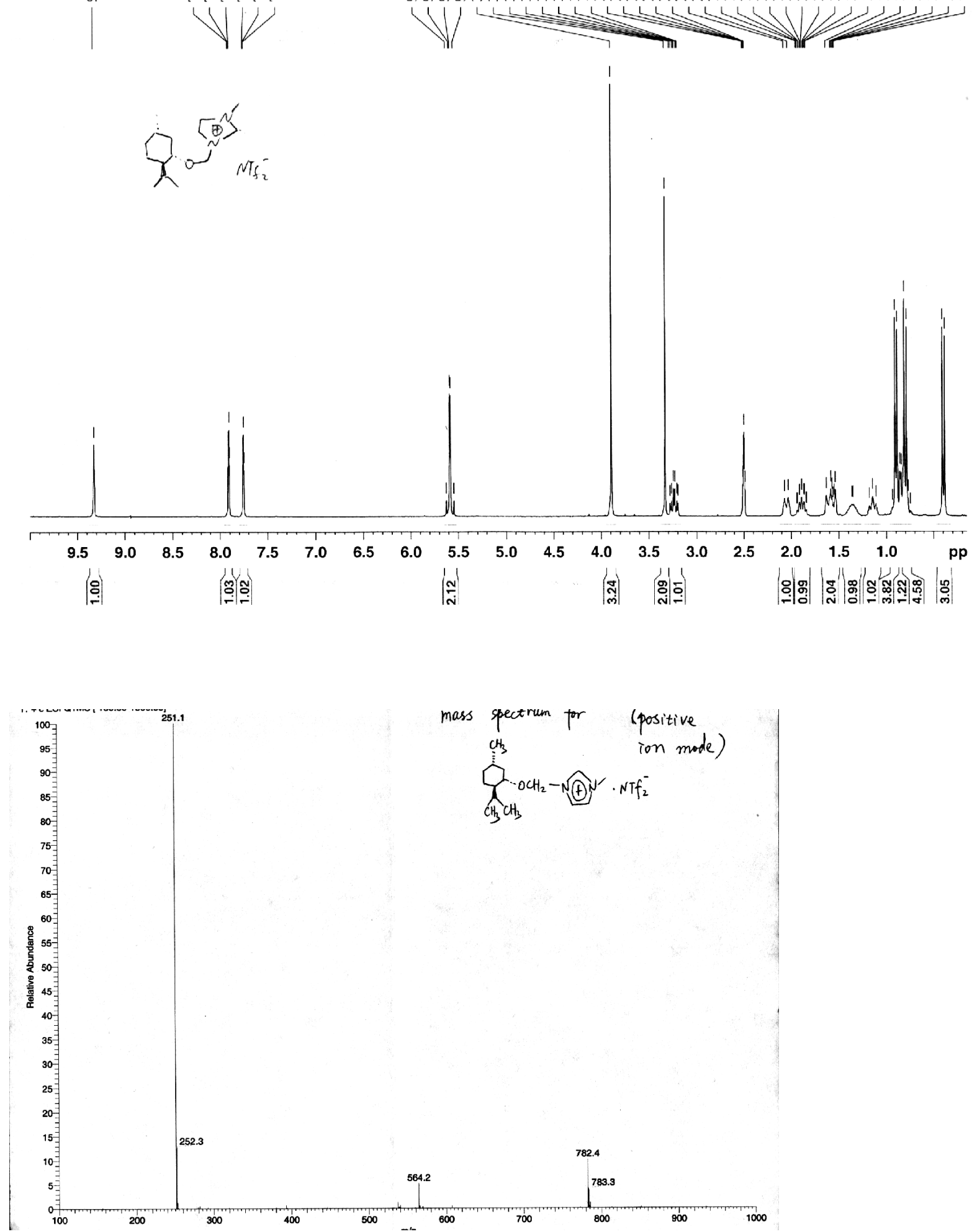
Spectra for 5
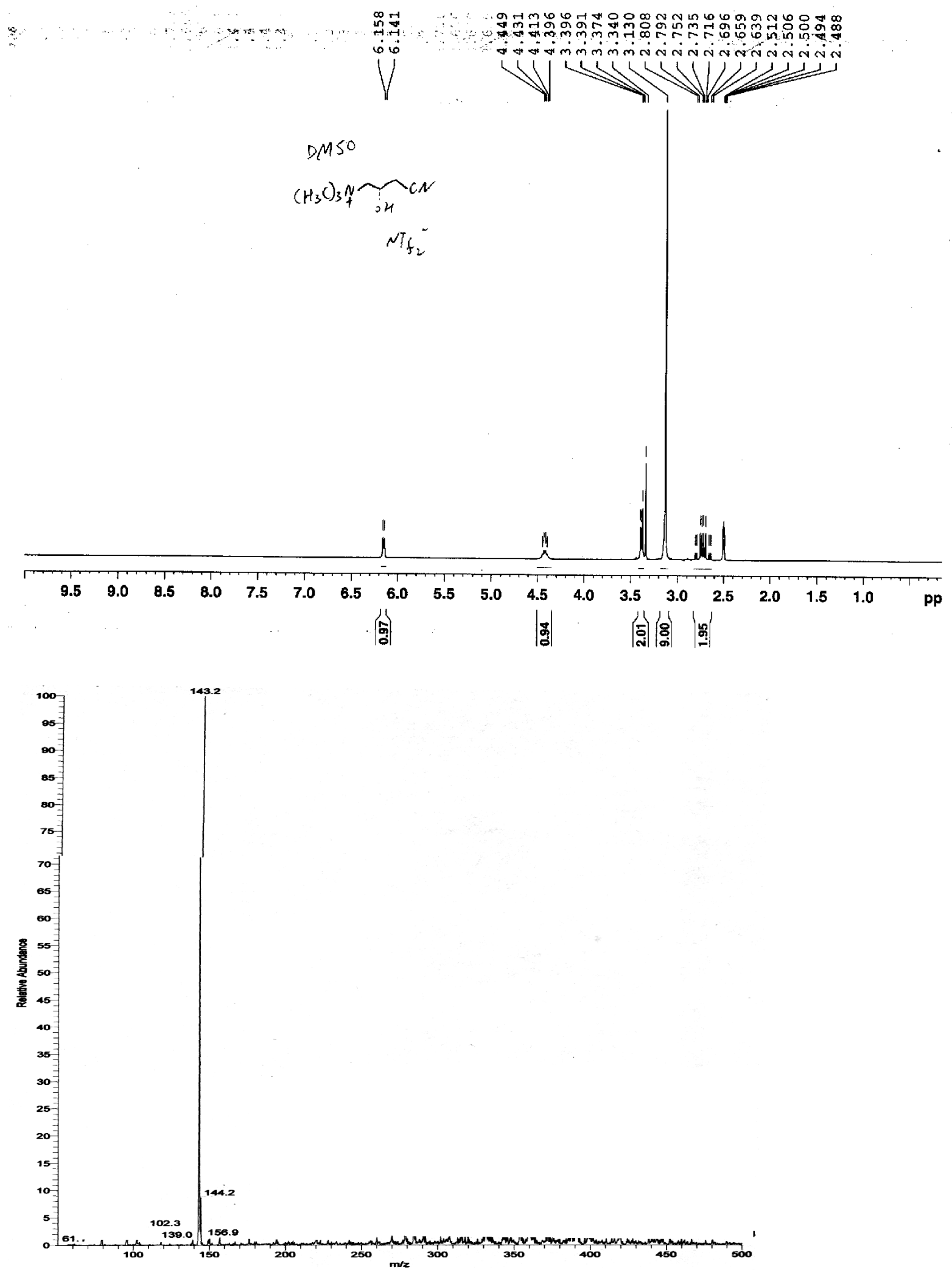
Spectra for 6.
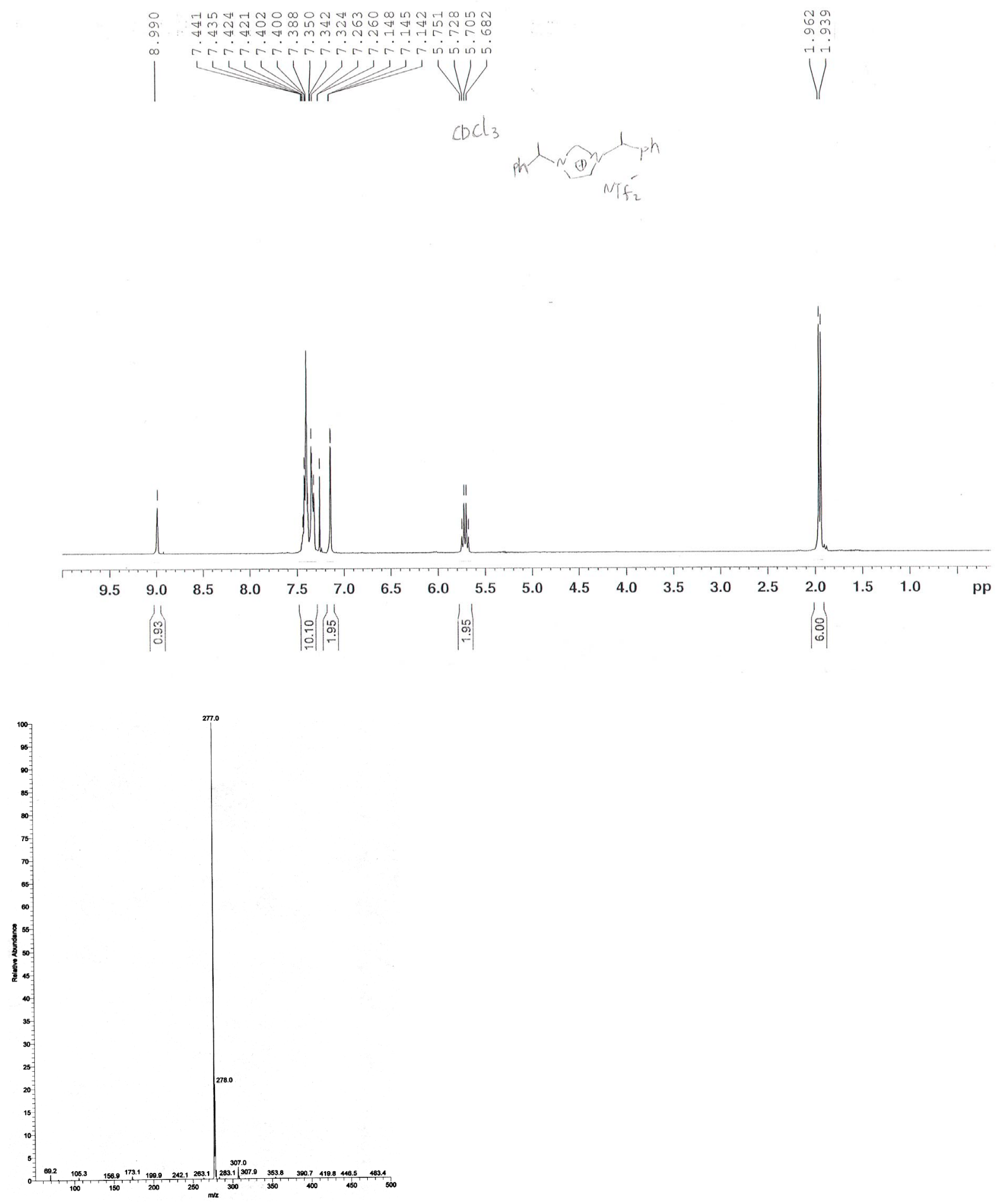
${ }^{1}$ Diels, O.; Alder, K. Justus Liebigs Ann. Chem. 1931, 486, 191-202.

${ }^{2}$ Wasserscheid, P.; Bösmann, A.; Bolm, C. Chem. Commun. 2002, 200-201.

${ }^{3}$ Herrmann, W. A.; Goossen, L. J.; Köcher, C.; Artus, G. R. Angew. Chem., Int. Ed. Engl.

1996, 35, 2805-2807. 